\title{
Absorbing aerosols: contribution of biomass burning and implications for radiative forcing
}

\author{
H. Gadhavi and A. Jayaraman \\ National Atmospheric Research Laboratory, Gadanki 517 112, India
}

Received: 1 July 2009 - Revised: 13 November 2009 - Accepted: 24 December 2009 - Published: 18 January 2010

\begin{abstract}
Absorbing aerosols supplements the global warming caused by greenhouse gases. However, unlike greenhouse gases, the effect of absorbing aerosol on climate is not known with certainty owing to paucity of data. Also, uncertainty exists in quantifying the contributing factors whether it is biomass or fossil fuel burning. Based on the observations of absorption coefficient at seven wavelengths and aerosol optical depth (AOD) at five wavelengths carried out at Gadanki $\left(13.5^{\circ} \mathrm{N}, 79.2^{\circ} \mathrm{E}\right)$, a remote village in peninsular India, from April to November 2008, as part of the "Study of Atmospheric Forcing and Responses (SAFAR)" pilot campaign we discuss seasonal variation of black carbon (BC) concentration and aerosol optical depth. Also, using spectral information we estimate the fraction of fossil-fuel and nonfossil fuel contributions to absorption coefficient and contributions of soot (Black Carbon), non-soot fine mode aerosols and coarse mode aerosols to AOD.
\end{abstract}

$\mathrm{BC}$ concentration is found to be around $1000 \mathrm{ng} / \mathrm{m}^{3}$ during monsoon months (JJAS) and around $4000 \mathrm{ng} / \mathrm{m}^{3}$ during pre and post monsoon months. Non-fossil fuel sources contribute nearly $20 \%$ to absorption coefficient at $880 \mathrm{~nm}$, which increases to $40 \%$ during morning and evening hours. Average AOD is found to be $0.38 \pm 0.15$, with high values in May and low in September. Soot contributes nearly $10 \%$ to the AOD. This information is further used to estimate the clear sky aerosol direct radiative forcing. Top of the atmosphere aerosol radiative forcing varies between -4 to $0 \mathrm{~W} \mathrm{~m}^{-2}$, except for April when the forcing is positive. Surface level radiative forcing is between -10 to $-20 \mathrm{~W} \mathrm{~m}^{-2}$. The net radiation absorbed within the atmosphere is in the range of 9 to $25 \mathrm{~W} \mathrm{~m}^{-2}$, of which soot contributes about 80 to $90 \%$.

Keywords. Atmospheric composition and structure (Aerosols and particles; Transmission and scattering of radiation) - Meteorology and atmospheric dynamics (Radiative processes)

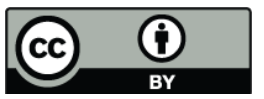

Correspondence to: $\mathrm{H}$. Gadhavi (harish@narl.res.in)

\section{Introduction}

Conventional wisdom is that aerosol exerts cooling effect on the Earth's climate and potentially offsetting the warming caused by greenhouse gases. However, cooling or warming by aerosols depends on the absorption property of aerosols as well as the reflectivity of the underlying earth's surface. Soot like particles are highly absorbing type aerosols (Bond and Bergstrom, 2006) and can play a role in warming of the earth's atmosphere. Estimated warming by black carbon is next only to $\mathrm{CO}_{2}$ (Jacobson, 2001). Soot aerosols also known as black carbon (BC) are produced when incomplete combustion takes place. The major sources of soot aerosols are diesel engines, forest fires and biomass burning. Absorption properties of soot particles depend highly on the combustion temperature and other material (e.g. organic carbon) emitted during the combustion processes (Bond and Bergstrom, 2006). Black carbon measurements made over various Indian cities in the past is found to be quite high compare to similar size cities in other part of the world (Ganguly et al., 2006a, b; Latha and Badarinath, 2005; Babu and Moorthy, 2002). However, bulk of Indian population lives in villages. Speculation has been made that most villagers though don't use fossil fuel run vehicles extensively, use biomass as cooking fuel and time-to-time burn agricultural waste. This could be a significant source of black carbon and comparable to vehicular and industrial emissions from big cities.

From April to November 2008, we carried out black carbon observation using aethalometer and aerosol optical depth measurement using skyradiometer at Gadanki campus of National Atmospheric Research Laboratory as part of a "Study of Atmsopheric Forcing and Responses (SAFAR)" pilot campaign (Jayaraman et al., 2010). Gadanki $\left(13.5^{\circ} \mathrm{N}, 79.2^{\circ} \mathrm{E}\right)$ is a rural location in peninsular India, and hence this campaign gave the opportunity to look at the aerosol characteristics in rural area. In the section Site-description we provide details of the surroundings and the meteorology of the observation site. In the Methodology section we provide details related to instruments and the algorithm used. In the Result section we discuss the seasonal and diurnal variation of black carbon,

Published by Copernicus Publications on behalf of the European Geosciences Union. 
aerosol optical depth and single scattering albedo. We also derived the contribution of fossil fuel derived BC to absorption coefficient, as well as contributions of fine and coarse mode aerosols and soot to AOD, which are discussed in the result section. All the findings are summarized in the summary section.

\section{Site description}

Observations were carried out at the campus of the National Atmospheric Research Laboratory (NARL) Gadanki $\left(13.5^{\circ} \mathrm{N}, 79.2^{\circ} \mathrm{E}\right)$. Observation site is about $2 \mathrm{~km}$ north east from main residential area of the Gadanki village. Most villagers use biofuel for cooking. Seasonally they also burn the agriculture waste in their farms. There is no major industrial activity around Gadanki, except a state highway connecting Tirupati and Bangalore passes through it. The highway has relatively low traffic density. Observations were carried out from the roof of a building located farthest in the north east direction of the campus using an inlet pipe mounted vertically, making a height of about 10 feet from the roof level and more than 30 feet from the ground level. Sky radiometer is also placed on the roof of the same building. NARL operates a diesel power generator as backup to support operations in case of disruption in main power supply line. If the generator is operated for a shorter period (less than one hour), aethalometer observations during that period plus next one hour are removed before calculating various statistics. If the generator is run more than that period, the whole day data is removed from the analysis. Thus observation bias from local sources are avoided.

Gadanki is a tropical warm location. Monthly mean temperature during April 2008 was $29.1^{\circ} \mathrm{C}$ with maximum temperature reaching as high as $41^{\circ} \mathrm{C}$. The monthly mean temperature came down to $24.1^{\circ} \mathrm{C}$ during November 2008 . Monthly mean relative humidity (RH) was $60 \%$ during April, which decreased to a value of $47.5 \%$ during May and increased continuously thereafter. During October and November, mean $\mathrm{RH}$ was $77 \%$. Unlike the northern and western India, where rain-fall largely occurs during summer monsoon months (June-September) Gadanki region experiences both summer (Southwest) and winter (Northeast) monsoons, and thus rain-fall was recorded during most of the months in the campaign period, from April to November. During May, June and August total rain-fall recorded was between $41 \mathrm{~mm}$ and $55 \mathrm{~mm}$. During July, September and October total rain-fall recorded was between $100 \mathrm{~mm}$ and $126 \mathrm{~mm}$. The maximum rainfall of $308 \mathrm{~mm}$ was recorded in November. Wind speed was low during April, around $1.21 \mathrm{~m} / \mathrm{s}$, which increased to $2 \mathrm{~m} / \mathrm{s}$ during May and June. July onward monthly mean wind speed decreased gradually with the lowest value $0.9 \mathrm{~m} / \mathrm{s}$ recorded in October. Overall wind direction was southerly and southeasterly during April, westerly from May to September and northeasterly during October and November.

\section{Methodology}

Black carbon measurements were carried out using seven channels Aethalometer (model AE31, Magee Scientific, USA; Hansen, 2005). Aethalometer uses quartz fiber filter tape through which air is passed for a fixed amount of time (typically $5 \mathrm{~min}$ ) with a selected constant flow rate (2 litre per minute in the present case). At the end of each measurement cycle changes in the filter transmission at seven wavelengths (namely $370 \mathrm{~nm}, 470 \mathrm{~nm}, 520 \mathrm{~nm}, 590 \mathrm{~nm}, 660 \mathrm{~nm}, 880 \mathrm{~nm}$ and $950 \mathrm{~nm}$ ) are recorded. The change in transmission is related to black carbon concentration as shown in the following equation,

$\mathrm{BC}=\frac{d(\mathrm{ATN})}{\sigma} \cdot \frac{A}{V}$

where BC is black carbon concentration, ATN is the attenuation of light through filter paper, $\sigma$ is the specific attenuation cross section $\left(\mathrm{m}^{2} / \mathrm{gm}\right)$, A is the spot area, $V$ is the volume of air passed through the filter. ATN and $\sigma$ are wavelength dependent quantities. BC concentration calculated using ATN at $880 \mathrm{~nm}$ channel with a $\sigma$ value of $16.6 \mathrm{~m}^{2} / \mathrm{gm}$ is considered standard for calculating $\mathrm{BC}$ concentration as there is no other major aerosol species which exhibits absorption at this wavelength. In the present work, unless mentioned specifically, the reported BC concentration values are for the $880 \mathrm{~nm}$ channel. Calibration is provided by the supplier which reports an error less than 5\% in the $\mathrm{BC}$ mass concentration values. However, factors such as shadowing effect (discussed in next paragraph) or ambient temperature variation can be different from that during the factory calibration process and hence an increase or decrease in the reported error is possible for actual field measurement. Though error in $\mathrm{BC}$ concentration at Gadanki could not be verified with other independent measurements, total error should not be exceeding $10 \%$ since proper care has been taken to maintain stable temperature of the aethalometer. Also error by shadowing effect is expected to be low as discussed in the next paragraph.

Data from other channels of the Aethalometer were utilized to obtain the spectral aerosol absorption coefficient (AAC). The absorption coefficient of particle embedded in the filter paper can be derived directly from attenuation using Eq. (2a),

$\beta_{\mathrm{ATN}}=d(\mathrm{ATN}) \cdot \frac{A}{V}$
$\beta_{\mathrm{a}}=\frac{\beta_{\mathrm{ATN}}}{C \cdot R(\mathrm{ATN})}$

where $\beta_{\mathrm{ATN}}$ is the absorption coefficient of the soot particles on filter paper and $\beta_{\mathrm{a}}$ is the absorption coefficient of soot particle suspended in air. $C$ is an empirical constant and $R(\mathrm{ATN})$ 
is an empirical function of ATN of the form shown in the Eq. (3). Other symbols have same meaning as in Eq. (1). The soot particles embedded in the filter paper can cause higher absorption compare to when they are suspended in air. This is because of multiple scattering within the filter matrix which increases the effective path length of the photon and hence increases the absorption by soot particles. However, as the number of soot particles increases on the filter paper, they can reduce the scattering within the filter paper. Hence, the change in attenuation by a fixed amount of soot particles will be less when filter paper is a highly loaded compare to when the filter paper is fresh. This effect, known as shadowing effect can be corrected as suggested by Weingartner et al. (2003). Equations (2b) and (3) show the empirical corrections for the shadowing effect. The constant $C$ in Eq. (2b) accounts for enhanced absorption of soot particles when they are embedded in the filter paper. The value of $C$ depends on the filter paper and apparatus. We have used a $C$ value of 2.14 following Weingartner et al. (2003). The term $R$ is a correction for shadowing effect. It is a function of amount of soot particles (accumulated attenuation) on the filter paper and the single scattering albedo of aerosols deposited on the filter paper. Scattering type aerosols when present on the filter paper along with soot particles, can partly compensate for reduction of scattering by the filter paper.

$R(\mathrm{ATN})=\left(\frac{1}{f}-1\right) \frac{\ln (\mathrm{ATN})-\ln (10 \%)}{\ln (50 \%)-\ln (10 \%)}+1$

Weingartner et al. (2003) suggest two methods to estimate $f$, one is using simultaneous measurements of scattering coefficient and other is using two identical aethalometers run sideby-side. Both the methods were not possible to apply in our case as the required instruments were not available at the time of these observations. Instead we used statistical approach to estimate the value of $f$. We first estimate the frequency distributions of $\beta$ for fixed values of ATN and the peak values from each frequency distribution are used to get $\beta$ as a function of ATN. In this way, we found $f$ equal to 1.17 . The value of $f$ indicates $8 \%$ error in absorption coefficient or BC mass concentration that would arise from shadowing effect. This might be representing upper end of the possible error. The actual error is expected to be less than this. Weingartner et al. (2003) have found $f$ equal to 1.12 for a typical car parking garage and 1.02 over high alpine site. Gadanki being a rural location one may expect values in between 1.02 and 1.12. We used shadowing effect correction to calculate absorption coefficient but haven't applied correction to get black carbon mass concentration. The BC mass concentration is derived using method suggested by the supplier which is described in the beginning of the section.

AAC is characterized by a power law equation of the form shown in Eq. (4)

$\operatorname{AAC}(\lambda)=K \lambda^{-\alpha^{\prime}}$

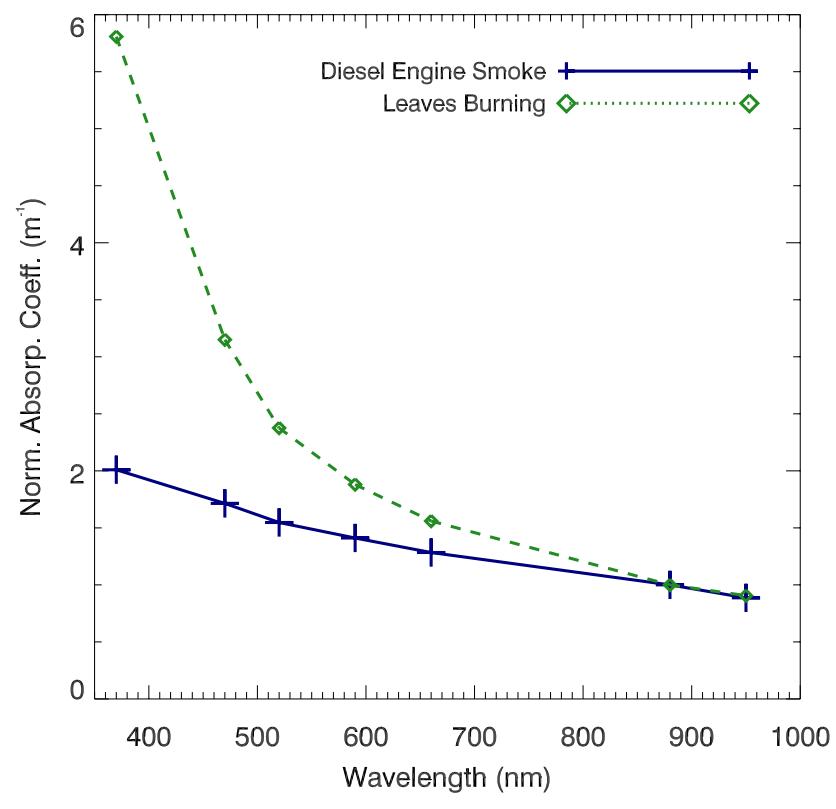

Fig. 1. Normalized absorption coefficient for two cases, one when diesel engine was running close to measurement site and another when leaf litter was burning. The values are normalized at $880 \mathrm{~nm}$.

where AAC is the aerosol absorption coefficient and $\lambda$ is the wavelength. Bergstrom et al. (2002) have shown using theoretical consideration that values of $\alpha^{\prime}$ will be 1.0 for small spherical particles having uniform refractive index. For the most urban regions where BC from fossil fuel dominants, it is indeed found to be 1.0 (Bergstrom et al., 2007; Kirchstetter et al., 2004; Schnaiter et al., 2005; Sandradewi et al., 2008a). In Fig. 1 measured absorption coefficient spectra are shown for observations made when a diesel engine was running close to the measurement site and another instance when leaf litter burning was taking place near the site. However, when particles are large (e.g. mineral dust) or organic carbon (OC) particles are present along with black carbon, values of $\alpha^{\prime}$ could be different. Values of $\alpha^{\prime}$ for soot particles emitted from biomass burning are reported between 1.5 and 3 (Bergstrom et al., 2004, 2007; Kirchstetter et al., 2004; Clarke et al., 2007). Dust particles also exhibit strong absorption in UV range. Values of $\alpha^{\prime}$ for dust particles are reported between 2 and 3 (Bergstrom et al., 2004, 2007; Fialho et al., 2005; Sandradewi et al., 2008b). Sandradewi et al. (2008b) have used $\alpha^{\prime}$ to separate contribution of wood burning from fossil fuel burning and verified it using contribution estimated using radiocarbon technique. Their method utilizes power law relation shown in Eq. (4) and linear addition of absorption coefficient of individual components as shown below.

$\mathrm{AAC}($ observed $)=\mathrm{AAC}($ fossil fuel $)+\mathrm{AAC}($ biomass burning $)$ 


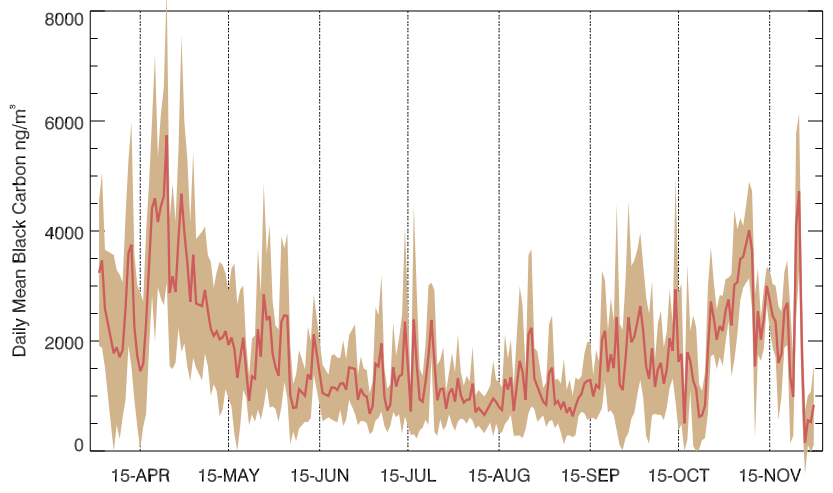

Fig. 2. Daily mean black carbon concentration observed over Gadanki. Gray area indicates the $\pm 1 \sigma$ standard deviation.

Ability or accuracy to separate the contributing components to absorption coefficient depends on the different $\alpha^{\prime}$ value for different sources. There is a significant difference in $\alpha^{\prime}$ value for soot generated from fossil fuel and that generated from biomass burning but the difference is small for soot from biomass burning and mineral dust. Hence we restrict our calculation for Gadanki for fossil fuel and biomass burning using $\alpha^{\prime}$ values between 1.0 and 2.0. Biomass burning contribution estimated in this manner is not strictly the biomass burning contribution rather non fossil fuel contribution (biomass + mineral dust). However, in light of other ancillary information such as observations of agricultural waste burning, rainfall, etc. we believe that contribution of mineral dust in non-fossil fuel component will be insignificant.

Sky-radiometer (Prede Ltd., Japan) is used to estimate aerosol optical depth (AOD) and column averaged single scattering albedo. Sky-radiometer measures direct sun light as well as sky radiance. In the present study we have utilized only sky radiance observations which were carried out at $10 \mathrm{~min}$ interval. The algorithm to estimate single scattering albedo and other microphysical parameter is based on Nakajima et al. (1996). Cloud screening is done based on various threshold values and consistency check embedded in the algorithm. Further cloud screening is done based on visual inspection of data along with log-book entry for sky condition.

We developed an algorithm to separate contributions of fine-mode, coarse mode and soot aerosol using spectral AOD as explained below. The spectral variation of aerosol optical depth can be characterized by Eq. (6a)

$\tau=\beta \cdot \lambda^{(-\alpha)}$

$\tau_{\text {aero }}=\sum \tau_{i}$

Traditionally $\beta$ is known as the turbidity parameter and $\alpha$ is known as the angstrom exponent. Value of $\alpha$ depends on the size distribution of aerosols. Coarse mode particles such as mineral dust, sea-salt, etc., have values of alpha around zero whereas for fine mode particles such as soot, sulphate, etc. have values of alpha around 1.6 (d'Almeida, 1991; Hess et al., 1998). The Eq. (6a) is also true for individual aerosol species. Component AODs can be added linearly as shown in Eq. (6b). Using this information one can write observed AOD as following

$\tau=\beta_{\mathrm{C}} \cdot \lambda^{\left(-\alpha_{\mathrm{C}}\right)}+\beta_{\mathrm{F}} \cdot \lambda^{\left(-\alpha_{\mathrm{F}}\right)}+\tau_{\mathrm{BC}}$

where subscript $\mathrm{C}$ denotes the coarse mode and $\mathrm{F}$ denotes fine mode. $\tau_{\mathrm{BC}}$ is the optical depth due to black carbon particles. We use surface measurements of $\mathrm{BC}$ concentration to estimate $\tau_{\mathrm{BC}}$ assuming soot particles are well mixed within the boundary layer up to a layer height of $2 \mathrm{~km}$. The soot component is subtracted from the total AOD and the remaining is used to get the coarse and fine mode components of AOD using values of $\alpha-0.04$ and 1.58 , respectively. We make two assumptions. The first is that the aerosols consists of only two modes fine and coarse and the second, which is more error prone, that the boundary layer height is fixed at $2 \mathrm{~km}$. Depending upon actual boundary layer height whether it is higher or lower than the assumed height, contribution of soot to total AOD will be underestimated or overestimated. In future when boundary layer height measurements will be available continuously, accuracy of the algorithm will improve nevertheless current algorithm serves a good purpose to give a qualitative picture of contribution of different aerosols.

\section{Results}

Daily mean values of black carbon concentration is shown in Fig. 2. Gray area around the mean values are $\pm 1 \sigma$ standard deviation. During the first half of May, BC concentration was high around $4000 \mathrm{ng} \mathrm{m}^{-3}$ and came down to around $1000 \mathrm{ng} \mathrm{m}^{-3}$ from June to August. From second half of the September to the last week of November, concentration went up and down twice, touching $4000 \mathrm{ng} \mathrm{m}^{-3}$ again during the first week of November. BC concentration observed over Gadanki is however low compared to values reported for few urban locations in India for same seasons. For example, over Hyderabad, BC concentration was around $6000 \mathrm{ng} \mathrm{m}^{-3}$ during June to September in year 2004 (Latha et al., 2005). Over Ahmedabad it was $1500 \pm 800 \mathrm{ng} \mathrm{m}^{-3}$ during June to September (averaged from 2003 to 2005) and $7300 \pm 3700 \mathrm{ng} \mathrm{m}^{-3}$ during October-November (Ganguly et al., 2006b). Over Trivendrum, a coastal city, BC concentration was between $1500 \mathrm{ng} \mathrm{m}^{-3}$ and $3000 \mathrm{ng} \mathrm{m}^{-3}$ during June to September for year 2000 and 2001 (Babu and Moorthy, 2002). Though there is difference in magnitude of $\mathrm{BC}$ concentration, seasonal variation pattern is similar to the ones observed at other locations, with low values during monsoon months and high value during pre-monsoon and postmonsoon months. Though the BC particles are not hygroscopic, rainfall can contribute to reduction of $\mathrm{BC}$ particles 


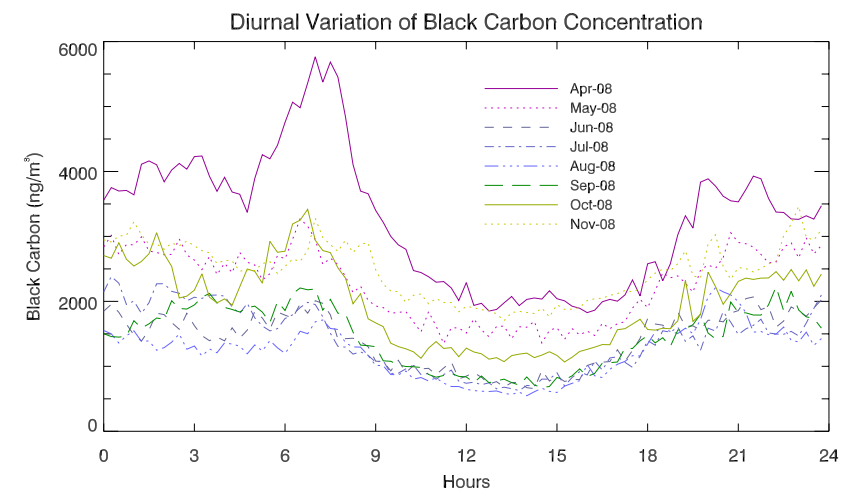

Fig. 3. Monthly mean diurnal variation of black carbon concentration observed at Gadanki.

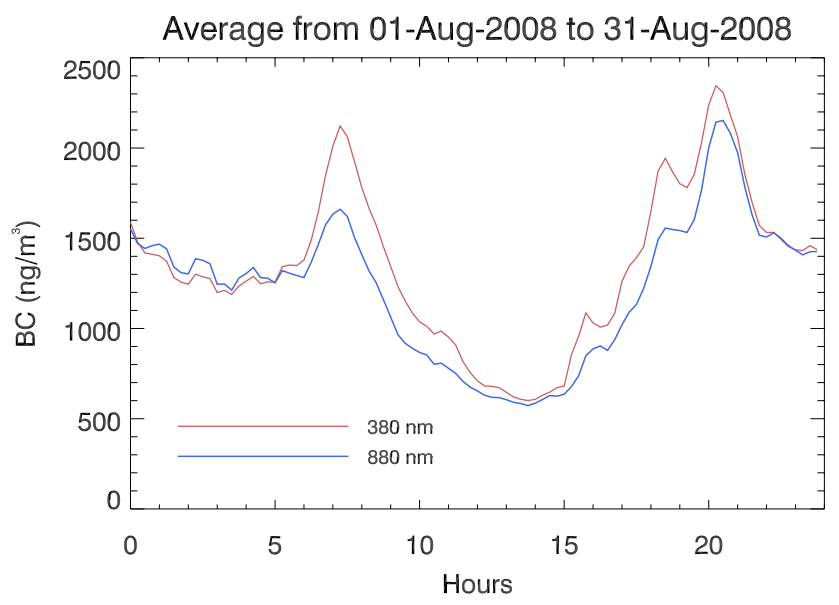

Fig. 4. Diurnal variation of $B C$ concentration obtained using UV channel $(370 \mathrm{~nm})$ and standard channel (880 nm data).

for example by reducing chances of forest fires and big scale waste burning. Also, condensation of secondary inorganic aerosols on BC particle can make them hygroscopic and get scavenged by precipitation. However, major contributing factor is the boundary layer dynamics in controlling the surface level concentration of $\mathrm{BC}$ and various other pollutants. Ventilation coefficient, which is the product of boundary layer height and mean wind speed is a measure of dispersion ability. Low ventilation coefficient allows more pollutants to accumulate and vice versa. Krishnan and Kunikrishnan (2004) studied the seasonal and diurnal variation of ventilation coefficient at Gadanki using Lower Atmospheric Wind Profiler (LAWP) data between March 1999 and April 2000 over Gadanki. They found that highest ventilation coefficient is during the monsoon because of high boundary layer height coupled with high wind speed and it is lowest during winter. The observed seasonal variation of $\mathrm{BC}$ at Gadanki is consistent with seasonal variation of ventilation coefficient.

Monthly mean diurnal variation in the observed $\mathrm{BC}$ concentration is shown in Fig. 3. The concentration value

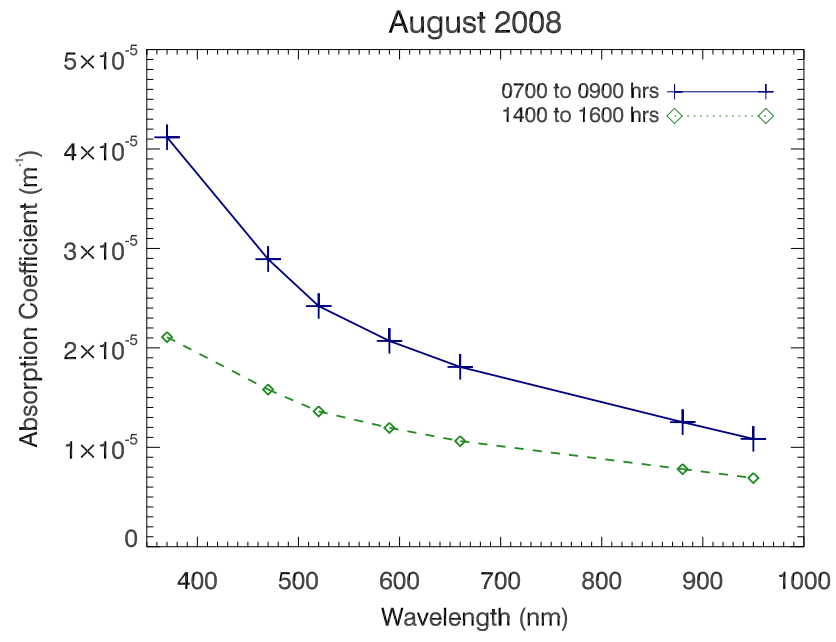

Fig. 5. Spectral characteristics of absorbing aerosols during morning hours and afternoon hours.

rises sharply between 05:00 and 08:00 h, thereafter decreases gradually till $14: 00 \mathrm{~h}$, rises again after $14: 00 \mathrm{~h}$ and attains second peak around 20:00 h. Similar diurnal variation is observed at over other locations e.g. Ahmedabad (Ganguly et al., 2006b), Hyderabad (Latha and Badarinath, 2005; Latha et al., 2005) and Trivendrum (Babu and Moorthy, 2002). Ganguly et al. (2006b) have found that the time of morning peak concentration correlates with sun-rise time and remains within two hours after sun-rise. Ganguly et al. (2006b), Latha and Badrinath (2005) and Babu and Moorthy (2002) have explained morning hour peak as result of combination of boundary layer dynamics and peak traffic hours. In Gadanki, number of vehicles plying is very small and any diurnal variation resulting from peak hour traffic activity will be insignificant. However being a rural place, morning and evening hours, people burn wood and other biomass for cooking. The signature of biomass burning during morning and evening hours is seen in the spectral dependence of absorption coefficient which is discussed next.

One interesting feature observed is the diurnal variation in the absorption spectrum. This is noticed when we compared the mass calculated using UV channel $(370 \mathrm{~nm})$ and standard channel $(880 \mathrm{~nm})$. Figure 4 shows the monthly mean diurnal variation of $\mathrm{BC}$ mass concentration calculated using specific attenuation cross-sections (Eq. 1) values $39.5 \mathrm{~m}^{2} / \mathrm{gm}$ and $16.6 \mathrm{~m}^{2} / \mathrm{gm}$ for $370 \mathrm{~nm}$ and $880 \mathrm{~nm}$ (Hansen, 2005). In case of soot particles emitted from diesel engines, concentration calculated at two channels would be the same. However, in the present case, UV channel reporting higher concentration indicate that the $\mathrm{BC}$ particles are emitted from sources such as biomass burning. In Fig. 5, average spectral AACs are shown for morning and afternoon hours for the month of August. Afternoon curve has $\alpha^{\prime}$ value close to 1 while morning curve has $\alpha^{\prime}$ value close to 2 indicating the prevalence 


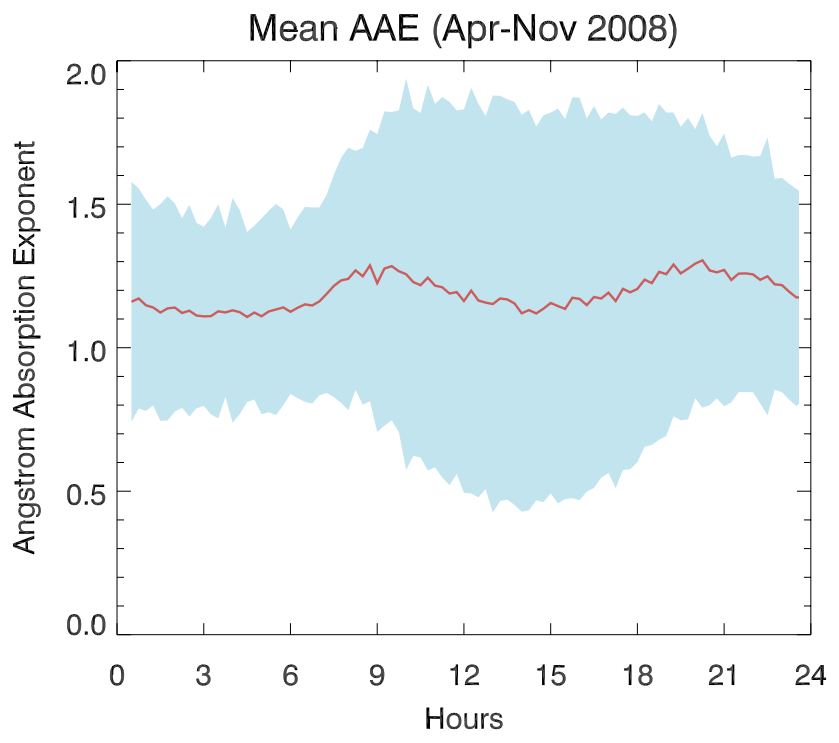

Fig. 6. Diurnal variation of angstrom absorption exponent (AAE).

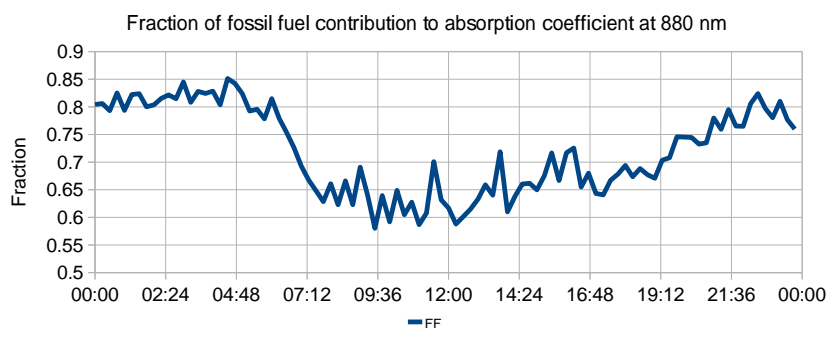

Fig. 7. Fraction of fossil fuel contribution to absorption coefficient.

of biomass burning during morning hours and its relative absence during noon hours. Figure 6 shows the observed diurnal variation in $\alpha^{\prime}$. Mean values are shown with solid line and shaded region is $\pm 1 \sigma$ standard deviation. Mean $\alpha^{\prime}$ values are around 1.2, which increases to 1.4 around $09: 00 \mathrm{~h}$ and then gradually decreases until 15:00 h. As the $\alpha^{\prime}$ characterizes the chemical properties of soot and not the total concentration of soot particles, the observed diurnal variation is a clear indication of the dominance of different sources at different time. Most rural household in India and in particular around Gadanki employs biomass burning for cooking. A typical day in villages starts and ends with cooking for the family. This increases the contribution of soot produced from biomass burning to the prevailing ambient level soot concentrations, which is captured well by the changes in the $\alpha^{\prime}$ value. We estimate that of the total absorption coefficient, about $80 \%$ is due to soot particles from fossil fuel burning, which however decreases to $60 \%$ during $08: 00$ to $10: 00 \mathrm{~h}$ in the morning and 18:00 to $20: 00 \mathrm{~h}$ in the late evening hours (Fig. 7).

Aerosol Optical Depth (AOD) measurements are possible only when significant portion of the sky is cloud free.

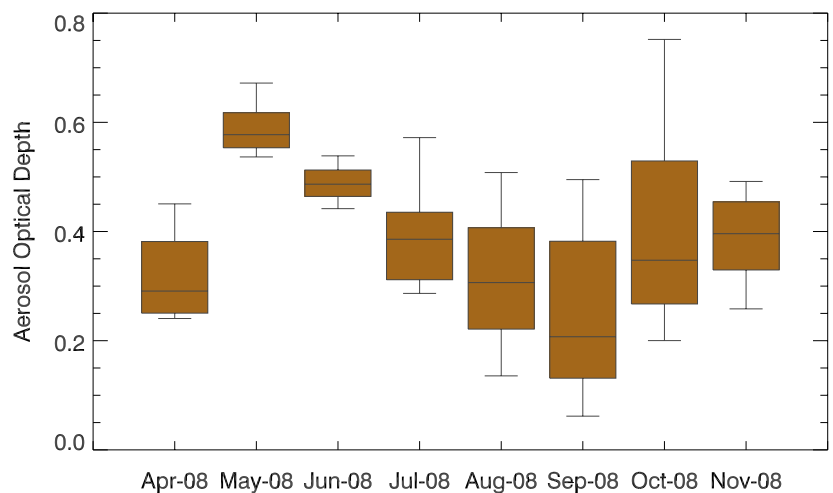

Fig. 8. Aerosol optical depth at $500 \mathrm{~nm}$ over Gadanki.

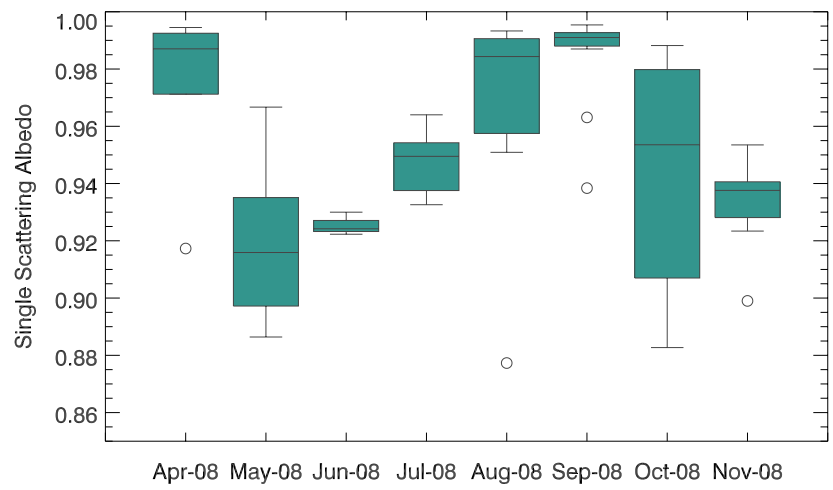

Fig. 9. Column average single scattering albedo estimated using skyradiometer data at $500 \mathrm{~nm}$ over Gadanki.

This limits the availability of AOD data. Between April and November 2008 about 56 days of AOD data could be obtained after cloud screening. Mean AOD at $500 \mathrm{~nm}$ over Gadanki was around $0.38 \pm 0.15$ between April and November. In Fig. 8, box-and-whisker plot for AOD at $500 \mathrm{~nm}$ is shown. Median AOD was high around 0.58 in May and decreased to 0.2 during September and then onward started increasing again. These AOD values are typical for a rural region.

Single scattering albedo, ratio of scattering coefficient to extinction (scattering + absorption) measured using the skyradiometer (Nakajima et al., 1996) was low in the start of May around 0.92 (Fig. 9), indicating higher absorption by aerosols. The value gradually increased to 0.99 in September, remained high for a while before started decreasing and came down to 0.93 by November. Spectral variation of absorption coefficient affects the spectral variation of single scattering albedo which in turn affects the radiative forcing efficiency of aerosols. We carried out radiative forcing simulations for typical conditions prevailing at Gadanki using radiative transfer model SBDART (Ricchiazzi et al., 1998). We used aerosols mass mixing ratio similar to continental polluted aerosol model (d'Almeida et al., 1991) for the 


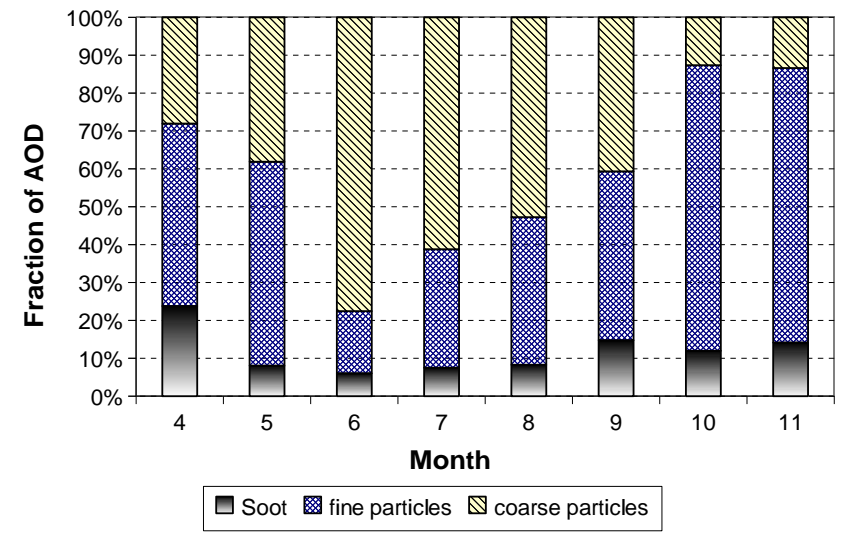

Fig. 10. Contribution of different aerosol components to the observed AOD. Fine mode component represent all the fine aerosols except soot.

simulations, i.e. $38 \%$ insoluble, $56 \%$ water soluble and $6 \%$ soot particles. Scattering properties for this aerosol model was calculated using the Optical Properties of Aerosols and Clouds (OPAC; Hess et al., 1996) software but absorption properties of soot particle are replaced with $\alpha^{\prime}$ equal to 1 (now onwards called case 1) and $\alpha^{\prime}$ equal to 2 (now onwards called case 2). While doing so we maintained that absorption coefficient at $880 \mathrm{~nm}$ is same in both the cases. When soot particles are only $6 \%$ of total aerosol mass, soot particles originating from biomass burning decreases forcing efficiency by $8 \%$ at top of the atmosphere and increases forcing efficiency at surface by $3 \%$. For cases when absorbing aerosols have higher mass mixing ratio, the difference in biomass and fossil fuel soot will become even more significant.

We have separated the contribution of fine-mode, coarse mode and soot aerosol in AOD as explained in the previous section. In Fig. 10, percentage of component AODs in total AODs is shown. Soot contributes about $10 \%$ of total AOD, whereas fine mode aerosols contribute more than $50 \%$ for April, May, September, October and November. In the months of June, July and August, contribution of coarse mode aerosols increases. During June to August surface wind speed was high compare to other months which can increase the coarse mineral dust concentration. However, estimated single scattering albedo from sun-photometer suggest an increase in scattering type aerosols. Mineral dust properties in models such as (OPAC) are based on Mie Scattering theory assuming spherical shape which can underestimate the scattering efficiency by dust particles. Possibilities are also there that mineral dust aerosols can be coated with scattering type aerosols and hence have more scattering or sea-salt aerosol transported all the way from Indian Ocean to Gadanki. In calculating radiative forcing we used sea-salt, water soluble and soot aerosols of OPAC to represent coarsemode, fine mode and black carbon aerosol optical depths.

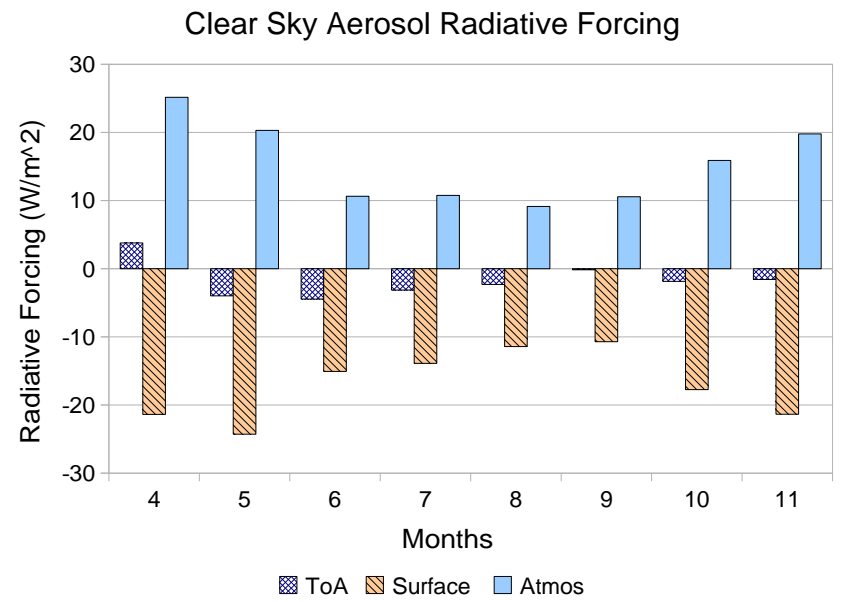

Fig. 11. Clear sky aerosol radiative forcing over Gadanki computed using monthly mean AOD values.

Top of the atmosphere (TOA) clear sky radiative forcing is found between -4 to 0 , except for April, when it is positive $3.8 \mathrm{~W} \mathrm{~m}^{-2}$ (Fig. 11). Surface radiative forcing is found to be between -24 and $-10 \mathrm{~W} \mathrm{~m}^{-2}$. The atmospheric radiative forcing, which is the difference between the surface and TOA forcing is between 9 and $25 \mathrm{~W} \mathrm{~m}^{-2}$. Low values for TOA forcing are due to brighter surface (vegetation type) over Gadanki. For similar magnitude of aerosol optical depth, Nakajima et al. (2003) have found $-7.5 \mathrm{~W} \mathrm{~m}^{-2}$ for TOA and $-31.08 \mathrm{~W} \mathrm{~m}^{-2}$ at surface level over Amami-Oshima $(28.15 \mathrm{~N}, 129.3 \mathrm{E})$ in the east China sea region which results in $23.58 \mathrm{~W} \mathrm{~m}^{-2}$ absorption in the atmosphere. Though soot particle contributes around $10 \%$ of aerosol optical depth, their forcing efficiency, which is the change in radiative forcing per unit change in AOD, is very high and hence they can contribute significantly to the total aerosol radiative forcing. This is because AOD is a measure of potential to reduce intensity of direct sun light whereas radiative forcing is a measure of change in total (direct + diffuse) radiation. The radiation removed from the direct beam due to scattering becomes available as diffuse radiation, whereas radiation absorbed is completely removed. Soot particles are responsible for about 80 to $90 \%$ of absorption within the atmosphere contributing about 8 to $17 \mathrm{~W} \mathrm{~m}^{-2}$, with exception in April when soot contribution is around $23 \mathrm{~W} \mathrm{~m}^{-2}$.

\section{Summary}

1. In rural areas soot from biomass burning used for cooking contribute about $40 \%$ to aerosol absorption during morning and late evening hours when the cooking activity is high.

2. Spectral dependence of absorption coefficient is different for soot coming from fossil fuel burning and 
biomass burning, the later has higher absorption at lower wavelengths.

3. Variations in the spectral dependence of aerosol absorption coefficient affect the aerosol radiative forcing of the atmosphere. Model radiative forcing calculations using $6 \%$ soot in the total aerosol mass concentration but with varying spectral dependence ( $\alpha^{\prime}=1$ for fossil fuel burning aerosols and $\alpha^{\prime}=2$ for biomass burning aerosols) show that biomass burning aerosols can decrease the radiative forcing by about $8 \%$ at top of the atmosphere. For higher mass ratio of absorbing aerosols this difference will increase further.

4. Mean aerosol optical depth is $0.38 \pm 0.15$, of which about $10 \%$ is due to soot.

5. Fine mode aerosols other than soot contributes nearly $50 \%$ during pre and post monsoon months, whereas during monsoon months coarse mode aerosols contributes $50 \%$ to $75 \%$.

Acknowledgements. Topical Editor F. D'Andrea thanks two anonymous referees for their help in evaluating this paper.

\section{References}

d'Almeida, G. A., Koepke, P., and Shettle, E. P.: Atmospheric Aerosols - Global Climatology and Radiative Characteristics, Deepak Publishing, p. 561, 1991.

Babu, S. S. and Moorthy, K. K.: Aerosol black carbon over a tropical coastal station in India, Geophys. Res. Lett., 29, 2098, doi:10.1029/2002GL015662, 2002.

Bergstrom, R. W., Russell, P. B., and Hignett, P.: Wavelength Dependence of the Absorption of Black Carbon Particles: Predictions and Results from the TARFOX Experiment and Implications for the Aerosol Single Scattering Albedo, J. Atmos. Sci., 59, 567-577, doi:10.1175/15200469(2002)059\\%3C0567:WDOTAO \\%3E2.0.CO, 2002.

Bergstrom, R. W., Pilewskie, P., Pommier, J., Rabbette, M., Russell, P. B., Schmid, B., Redemann, J., Higurashi, A., Nakajima, T., and Quinn, P. K.: Spectral absorption of solar radiation by aerosols during ACE-Asia, J. Geophys. Res., 109, D19S15, doi:10.1029/2003JD004467, 2004.

Bergstrom, R. W., Pilewskie, P., Russell, P. B., Redemann, J., Bond, T. C., Quinn, P. K., and Sierau, B.: Spectral absorption properties of atmospheric aerosols, Atmos. Chem. Phys., 7, 5937-5943, 2007 , http://www.atmos-chem-phys.net/7/5937/2007/.

Bond, T. C. and Bergstrom, R. W.: Light Absorption by Carbonaceous Particles: An Investigative Review, Aerosol Sci. Technol., 40, 27-67, 2006.

Clarke, A., Mcnaughton, C., Kapustin, V., Shinozuka, Y., Howell, S., Dibb, J., Zhou, J., Anderson, B., Brekhovskikh, V., Turner, H., and Pinkerton, M.: Biomass burning and pollution aerosol over North America: Organic components and their influence on spectral optical properties and humidification response, J. Geophys. Res., 112, D12S18, doi:10.1029/2006JD007777, 2007.
Fialho, P., Hansen, A., and Honrath, R.: Absorption coefficients by aerosols in remote areas: a new approach to decouple dust and black carbon absorption coefficients using sevenwavelength Aethalometer data, J. Aerosol Sci., 36, 267-282, doi:10.1016/j.jaerosci.2004.09.004, 2005.

Ganguly, D., Jayaraman, A., Rajesh, T. A., and Gadhavi, H.: Wintertime aerosol properties during foggy and nonfoggy days over urban center Delhi and their implications for shortwave radiative forcing, J. Geophys. Res., 2006, 111, D15217, doi:10.1029/2005JD007029, 2006a.

Ganguly, D., Jayaraman, A., and Gadhavi, H.: Physical and optical properties of aerosols over an urban location in western India: Seasonal variabilities, J. Geophys. Res., 111, D24206, doi:10.1029/2006JD007392, 2006b.

Hansen, A. D. A.: The Aethalometer - User Manual, Magee Scientific Company, California USA., version 2005.07, 2005.

Hess, M., Koepke, P., and Schult, I.: Optical Properties of Aerosols and Clouds: The Software Package OPAC., B. Am. Meteorol. Soc., 79, 831-844, 1998.

Jacobson, M. Z.: Strong radiative heating due to the mixing state of black carbon in atmospheric aerosols, Nature, 409, 695-697, doi:10.1038/35055518, 2001.

Jayaraman, A., Venkat Ratnam, M., Patra, A. K., et al.: Study of Atmospheric Forcing and Responses (SAFAR) campaign: overview, Ann. Geophys., 28, 89-101, 2010, http://www.ann-geophys.net/28/89/2010/.

Kirchstetter, T. W., Novakov, T., and Hobbs, P. V.: Evidence that the spectral dependence of light absorption by aerosols is affected by organic carbon, J. Geophys. Res., 109, D21208, doi:10.1029/2004JD004999, 2004.

Krishnan, P. and Kunhikrishnan, P. K.: Temporal variations of ventilation coefficient at a tropical Indian station using UHF wind profiler, Current Science, 86, 447-451, 2004.

Latha, K. and Badarinath, K.: Seasonal variations of black carbon aerosols and total aerosol mass concentrations over urban environment in India, Atmos. Environ., 39, 4129-4141, doi:10.1016/j.atmosenv.2005.04.004, 2005.

Latha, M. K., Badarinath, K. V. S., and Reddy, M. P.: Scavenging efficiency of rainfall on black carbon aerosols over an urban environment, Atmos. Sci. Lett., 6, 148-151, doi:10.1002/asl.108, 2005.

Nakajima, T., Tonna, G., Rao, R., Boi, P., Kaufman, Y., and Holben, B.: Use of sky brightness measurements from ground for remote sensing of particulate polydispersions, Appl. Optics, 35, 2672 2686, doi:10.1364/AO.35.002672, 1996.

Nakajima, T., Sekiguchi, M., Takemura, T., Uno, I., Higurashi, A., Kim, D., Sohn, B. J., Oh, S.-N., Nakajima, T. Y., Ohta, S., Okada, I., Takamura, T., and Kawamoto, K.: Significance of direct and indirect radiative forcings of aerosols in the East China Sea region, J. Geophys. Res., 108, 8658, doi:10.1029/2002JD003261, 2003.

Ricchiazzi, P., Yang, S., Gautier, C., and Sowle, D.: SBDART: A research and teaching software tool for plane parallel radiative transfer in the earth's atmosphere, B. Am. Meteorol. Soc., 79, 2101-2114, 1998.

Sandradewi, J., Prévôt, A. S., Weingartner, E., Schmidhauser, R., Gysel, M., and Baltensperger, U.: A study of wood burning and traffic aerosols in an Alpine valley using a multiwavelength Aethalometer, Atmos. Environ., 42(1), 101-112, 
doi:10.1016/j.atmosenv.2007.09.034, 2008a.

Sandradewi, J., Prévôt, A. S., Szidat, S., Perron, N., Alfarra, R. M., Lanz, V. A., Weingartner, E., and Baltensperger, U.: Using Aerosol Light Absorption Measurements for the Quantitative Determination of Wood Burning and Traffic Emission Contributions to Particulate Matter, Environ. Sci. Technol., 42(9), 33163323, doi:10.1021/es702253m, 2008b.

Schnaiter, M., Linke, C., Möhler, O., Naumann, K. H., Saathoff, H., Wagner, R., Schurath, U., and Wehner, B.: Absorption amplification of black carbon internally mixed with secondary organic aerosol, J. Geophys. Res., 110, D19204, doi:10.1029/2005JD006046, 2005.
Weingartner, E., Saathoff, H., Schnaiter, M., Streit, N., Bitnar, B., and Baltensperger U.: Absorption of light by soot particles: determination of the absorption coefficient by means of aethalometers, J. Aerosol Sci., 34(10), 1445-1463, doi:10.1016/S00218502(03)00359-8, 2003. 